\title{
Cyanidin-3-glucoside isolated from mulberry fruits protects pancreatic $\beta$-cells against glucotoxicity-induced apoptosis
}

\author{
JONG SEOK LEE ${ }^{1,2^{*}}$, YOUNG RAE KIM ${ }^{1 *}$, JUN MYOUNG PARK $^{1}$, \\ YOUNG EON KIM ${ }^{3}$, NAM IN BAEK ${ }^{4}$ and EOCK KEE HONG ${ }^{1}$ \\ ${ }^{1}$ Department of Bioengineering and Technology, College of Engineering, Kangwon National University, \\ Chuncheon, Gangwon-do 200-701; ${ }^{2}$ National Institute of Biological Resources, Incheon, 404-708; \\ ${ }^{3}$ Division of Metabolism and Functionality Research, Korea Food Research Institute, Seongnam, \\ Gyeonggi-Do 463-746; ${ }^{4}$ Department of Oriental Medicinal Materials and Processing, \\ Kyung Hee University, Yongin, Gyeonggi-do 446-701, Republic of Korea
}

Received April 1, 2014; Accepted October 31, 2014

DOI: $10.3892 / \mathrm{mmr} .2014 .3078$

\begin{abstract}
The present study investigated the cytoprotective effects of cyanidin-3-glucoside (C3G), isolated from mulberry fruits, on the glucotoxicity-induced apoptosis of pancreatic $\beta$-cells to evaluate the antidiabetic effects of this compound. MIN6N pancreatic $\beta$-cells were used to investigate the cytoprotective effects of $\mathrm{C} 3 \mathrm{G}$. In addition, the effects of $\mathrm{C} 3 \mathrm{G}$ on the glucotoxicity-induced apoptosis of pancreatic $\beta$-cells was evaluated using MTT assay, immunofluorescent staining, flow cytometric and western blot analyses. The pancreatic $\beta$-cells cultured under high glucose conditions exhibited distinct apoptotic features. C3G decreased the generation of intracellular reactive oxygen species, DNA fragmentation and the rate of apoptosis. $\mathrm{C} 3 \mathrm{G}$ also prevented pancreatic $\beta$-cell apoptosis induced by high glucose conditions by interfering with the intrinsic apoptotic pathways. In addition, C3G treatment resulted in increased insulin secretion compared with treatment with high glucose only. In conclusion, the results of the present study suggested that $\mathrm{C} 3 \mathrm{G}$ obtained from mulberry fruits may be a potential phytotherapeutic agent for the prevention of diabetes.
\end{abstract}

\section{Introduction}

At present, there is a lack of effective treatment for diabetes mellitus and the current antidiabetic therapies, including

Correspondence to: Professor Eock Kee Hong, Department of Bioengineering and Technology, College of Engineering, Kangwon National University, 192-1 Hyoja-2-dong, Chuncheon, Gangwon-do 200-701, Republic of Korea

E-mail: ekhong@kangwon.ac.kr

*Contributed equally

Key words: diabetes, glucotoxicity, mulberry, apoptosis, anthocyanin insulin injection and administering of hypoglycemic agents usually have various side effects (1). In addition, these agents are relatively ineffective against certain long-term diabetic complications and are expensive (2). Therefore, the development of antidiabetic agents derived from natural sources may offer a promising solution to prevent the adverse effects of current antidiabetic therapies (3).

The pharmacological effects of various medicinal plants have been previously examined, including effects on the regulation of blood glucose levels and cell death in high glucose-induced oxidative stress, which is caused by the excessive generation of intracellular reactive oxygen species (ROS) (4-6). Anthocyanins are a group of naturally derived plant pigments, which are used as orally administered therapeutic agents due to their nontoxic antioxidative, anti-inflammatory and anticancer properties $(7,8)$. Previous studies have suggested that the different types of anthocyanins, including cyanidin, delphinidin and peonidin isolated from natural products may be useful in the prevention and/or treatment of aging, cancer, arteriosclerosis, inflammation and diabetes $(9,10)$. However, the potential antidiabetic effects of cyanidin-3-glucoside (C3G), which is isolated from mulberry fruits, on high glucose-induced apoptosis remain to be elucidated.

Therefore, the present study investigated whether $\mathrm{C} 3 \mathrm{G}$, isolated from mulberry fruits, protected MIN6N pancreatic $\beta$-cells against high glucose-induced oxidative stress from high glucose conditions in the pancreas via modulation of cell signaling pathways.

\section{Materials and methods}

Materials. Dulbecco's modified Eagle's medium (DMEM), fetal bovine serum (FBS), penicillin-streptomycin (PS) and trypsin-EDTA were purchased from Gibco-BRL (Grand Island, NY, USA). The dichlorodihydrofluorescein-diacetate $\left(\mathrm{H}_{2} \mathrm{DCF}-\mathrm{DA}\right)$ apoptotic assay kit and nuclear extraction kit were obtained from Molecular Probes (Carlsbad, CA, USA). The rat/mouse insulin enzyme-linked immunosorbent assay kit was obtained from Linco Research, Inc. (St. Charles, MO, 
USA). Kuromanin chloride (C3G standard), Hoechst 33342 and the mitochondria isolation kit were purchased from Sigma-Aldrich (St. Louis, MO, USA). Antibodies against c-Jun $\mathrm{NH}_{2}$-terminal kinase (JNK; 1:1,000 dilution; rabbit polyclonal antibody; \#9252), phosphorylated (p-)JNK (1:1,000 dilution; Thr183/Tyr185 mouse monoclonal antibody; \#9255S), extracellular signal-related kinase (ERK; 1:1,000 dilution; rabbit monoclonal antibody; \#4695), p-ERK (1:1,000 dilution; Thr202/Tyr204 rabbit polyclonal antibody; \#9101S), p38 (1:1,000 dilution; rabbit polyclonal antibody; \#9212), p-p38 (1:1,000 dilution; Thr180/Tyr182 rabbit monoclonal immunoglobulin (Ig)G antibody; \#4631S), nuclear factor- $\kappa \mathrm{B}(\mathrm{NF}-\kappa \mathrm{B})$ p65 (1:1,000 dilution; rabbit polyclonal antibody; \#3034) and horseradish peroxidase (HRP)-linked anti-rabbit IgG (1:2,000 dilution; \#7074) were purchased from Cell Signaling Technology, Inc. (Beverly, MA, USA). Antibodies against $\beta$-actin (1:1,000 dilution; mouse monoclonal $\mathrm{IgG}_{1}$; sc-47778), Bcl-2 (1:1,000 dilution; mouse monoclonal $\operatorname{IgG}_{1}$; sc-7382), Bax (1:1,000 dilution; rabbit polyclonal IgG; sc-493), caspase-3 (1:1,000 dilution; mouse monoclonal $\left.\mathrm{IgG}_{2 \mathrm{a}} ; \mathrm{sc}-7272\right)$ and HRP-linked goat anti-mouse IgG (1:2,000 dilution; sc-2005) were purchased from Santa Cruz Biotechnology, Inc. (Dallas, TX, USA). All other chemicals were obtained from Sigma-Aldrich.

Extraction and identification of anthocyanin. Mulberry fruit was purchased from a local company (Sujuchon, Yecheon, Korea). For anthocyanin extraction, the mulberry fruits were placed in $70 \%$ ethanol for $24 \mathrm{~h}$ at room temperature (RT). Following centrifugation of the extract $(600 \mathrm{x} \mathrm{g}, 20 \mathrm{~min})$, the supernatants were filtered with Whatman filter paper $(0.45 \mu \mathrm{m})$, concentrated using a vacuum rotary evaporator (Eyela, Tokyo, Japan), redissolved in triple distilled water and lyophilized using a freeze dryer (IlShin, Seoul, Korea). The powder was soaked in $n$-hexane for $24 \mathrm{~h}$ to remove the fats and oils. The anthocyanins in the powder were then extracted with acidified methanol (methanol and $1.0 \mathrm{~N} \mathrm{HCl} ; 85: 15$, v/v), centrifuged at $12,000 \mathrm{x}$ g for $15 \mathrm{~min}$ to remove the precipitate and then filtered through a $0.45 \mu \mathrm{m}$ filter. The purified anthocyanin extract was evaporated at $46^{\circ} \mathrm{C}$ to dryness and stored at $4^{\circ} \mathrm{C}$. The anthocyanin powder was redissolved in the culture medium and filtered using a $0.22 \mu \mathrm{m}$ filter prior to cell culture. The pure C3G standard and purified anthocyanin, isolated from mulberry fruits, were identified using high-performance liquid chromatography (HPLC) retention time and their purity was $>99 \%$ (data not shown). Reversed-phase HPLC was performed using Waters 486 detector (Waters, Milford, MA, USA) under the following conditions: Column, $\mu$ BondapakC18 (Waters; 3.9x300 mm); flow rate, $0.5 \mathrm{ml} / \mathrm{min}$; injection volume, $10 \mu \mathrm{l}$; solvent, methanol/ $\mathrm{H}_{2} \mathrm{O} /$ formic acid (75:20:5); and column temperature, $46^{\circ} \mathrm{C}$. The absorbance was recorded at $520 \mathrm{~nm}$ using a Thermo Spectronic Genesys ultraviolet-visible spectrophotometer (Spectronic Instruments; Thermo Fisher Scientific, Waltham, MA, USA).

Cell culture. The MIN6N pancreatic $\beta$-cells were derived from a mouse pancreatic islet. The cells were provided by Professor H. Y. Kwon (College of Medicine, Hallym University, Chuncheon, Korea). The MIN6N $\beta$-cells were cultured in DMEM (5.5 mM glucose) supplemented with $10 \%$ inactivated
FBS and $1 \%$ PS and were maintained at $37^{\circ} \mathrm{C}$ in a humidified $5 \% \mathrm{CO}_{2}$ incubator. The cells were cultured to $85 \%$ confluence and were harvested using $0.25 \%$ trypsin-EDTA. The cells were then subcultured in 6- or 12-well plates for $12 \mathrm{~h}$ until they reached confluence. The cells were then treated with various concentrations $(0,10,20,50,70,100$ and $200 \mu \mathrm{g} / \mathrm{ml})$ of $\mathrm{C} 3 \mathrm{G}$ for $18 \mathrm{~h}$ and then cultured for an additional $18 \mathrm{~h}$ in DMEM containing either $25 \mathrm{mM}$ glucose or $25 \mathrm{mM}$ mannitol (mannitol with $5.5 \mathrm{mM}$ glucose in culture medium). The cells were maintained in these culture conditions for all experiments.

Cell viability assay. The viability of the treated cells was measured using the 3-(4,5-dimethylthiazol-2-yl)-2,5-diphenyltetrazolium bromide (MTT) assay. Briefly, $500 \mu \mathrm{g} / \mathrm{ml}$ MTT solution was added to each well and incubated for $2.5 \mathrm{~h}$ at $37^{\circ} \mathrm{C}$. The formazan crystals in each well were dissolved in isopropyl alcohol and the absorbance of each well was measured at $595 \mathrm{~nm}$ using an ELISA microplate reader (Bio-Rad model 550; Bio-Rad Laboratories Inc., Hercules, USA).

Measurement of intracellular ROS and image analysis. Following treatment of the cells, $5 \mu \mathrm{M} \mathrm{H}_{2}$ DCF-DA in phosphate-buffered saline (PBS, pH 7.38; Gibco-BRL) was added and the fluorescence was measured at excitation and emission wavelengths of $485 \mathrm{~nm}$ and $535 \mathrm{~nm}$, respectively, using a microplate spectrofluorometer (Molecular Devices Corp., Sunnyvale, CA, USA). The production of intracellular ROS was determined by image analysis of the cells, which were seeded into coverslip-loaded 6-well plates. Subsequently, $\mathrm{H}_{2}$ DCF-DA solution (500 $\mu \mathrm{l}$ per well) was added to each well of the plate, which was incubated for $2 \mathrm{~h}$ at $37^{\circ} \mathrm{C}$. Images of the stained cells were acquired using a fluorescence microscope (Nikon Eclipse TE 300; Nikon, Tokyo, Japan).

Measurement of DNA fragmentation. The cells were treated with Hoechst 33342, a dye used to detect DNA condensation and/or fragmentation, followed by incubation at RT for $15 \mathrm{~min}$. Images of the stained cells were acquired using a fluorescence microscope to examine the degree of DNA fragmentation.

Flow cytometric analysis. The apoptotic cells were examined using a fluorescein isothiocyanate (FITC)-labeled Annexin V/propidium iodide (PI) apoptosis detection kit (Moleclular Probes, Carlsbad, CA, USA) according to the manufacturer's instructions. The treated cells were harvested and washed with PBS and then centrifuged at $600 \mathrm{x}$ g for 5 min to collect the cell pellet. Subsequently, the cells were resuspended in binding buffer (10 mM HEPES, $140 \mathrm{mM}$ $\mathrm{NaCl}, 2.5 \mathrm{mM} \mathrm{CaCl} 2 ; \mathrm{pH}$ 7.4) and stained with FITC-labeled Annexin V/PI at RT for 15 min in light-protected conditions. Flow cytometric analysis was performed using a FACSCalibur flow cytometer (Becton Dickinson, Mountain View, CA, USA) within $1 \mathrm{~h}$ of the supravital staining. The apoptotic cell rate was calculated as the sum of cells in the early and late phases of apoptosis divided by the total number of events.

Western blot analysis. The treated cells were washed in 1X PBS and lysed in lysis buffer [10 mM Tris- $\mathrm{HCl}(\mathrm{pH} 7.5), 10 \mathrm{mM}$ 


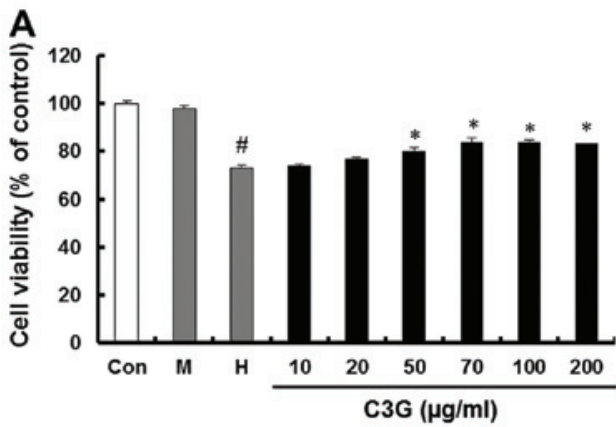

C

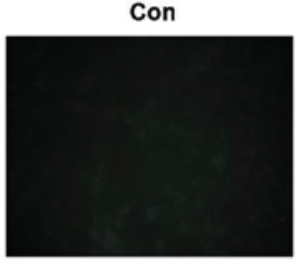

B

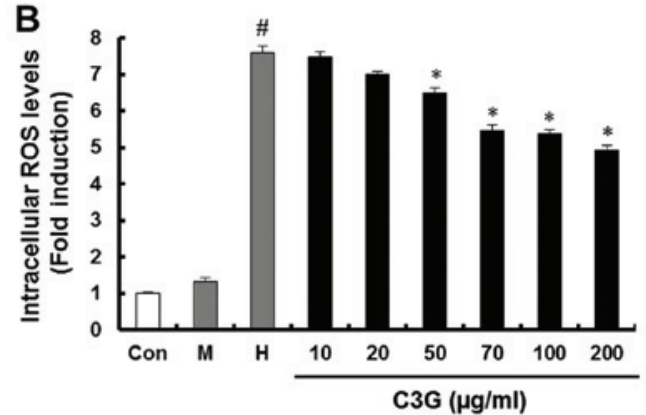

H

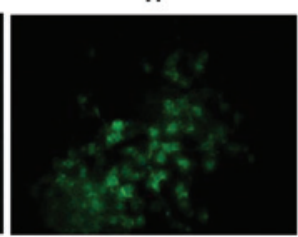

$\mathrm{C} 3 \mathrm{G}+\mathrm{H}$

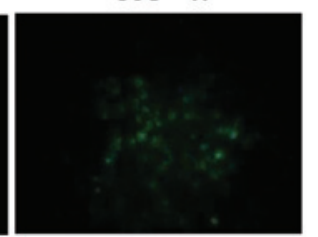

Figure 1. Effect of C3G on cell viability and ROS generation in the MIN6N $\beta$-cells. The cells were cultured with $5.5 \mathrm{mM}$ glucose (Con), $25 \mathrm{mM}$ mannitol (M), $25 \mathrm{mM}$ glucose $(\mathrm{H})$ and indicated doses of $\mathrm{C} 3 \mathrm{G}$ with $25 \mathrm{mM}$ glucose $(\mathrm{C} 3 \mathrm{G}+\mathrm{H})$. (A) Cell viability was determined using an 3-(4,5-dimethylthiazol-2-yl)-2,5-diphenyltetrazolium bromide assay. (B) Levels of intracellular ROS were measured using the $\mathrm{H}_{2}$ DCF-DA method. Data represent the mean \pm standard error of three independent experiments. ${ }^{*} \mathrm{P}<0.05$ vs. Con; " $\mathrm{P}<0.05$, vs. H group. (C) Representative fluorescence images demonstrate the increase in green fluorescence intensity of the DCF produced by ROS (magnification, 400x). CG3, cyanidin-3-glucoside; ROS, reactive oxygen species; Con, control; $\mathrm{H}_{2} \mathrm{DCF}-\mathrm{DA}$, dichlorodihydrofluorescein-diacetate.

$\mathrm{NaH}_{2} \mathrm{PO}_{4} / \mathrm{NaHPO}_{4}(\mathrm{pH} 7.5), 130 \mathrm{mM} \mathrm{NaCl}, 1 \%$ Triton X-100, $10 \mathrm{mM}$ NaPPi, $1 \mathrm{mM}$ phenylmethylsulphonyl fluoride, $2 \mu \mathrm{g} / \mathrm{ml}$ pepstatin A] for 40 min on ice. The lysates were centrifuged at $12,000 \mathrm{xg}$ for $30 \mathrm{~min}$ at $4^{\circ} \mathrm{C}$. The supernatant was then collected and the protein content of the supernatant was measured using a Bio-Rad protein assay kit (Bio-Rad Laboratories, Inc.) prior to analysis. The total or fractionated protein samples were loaded and separated using sodium dodecyl sulfate-polyacrylamide gel electrophoresis and transferred onto nitrocellulose membranes (Bio-Rad Laboratories, Inc.). The membranes were inhibited with 5\% non-fat powdered milk in $1 \mathrm{X}$ Tris-buffered saline containing $0.1 \%$ Tween-20 (TBS-T) for $1 \mathrm{~h}$ and were incubated with primary antibodies at $4^{\circ} \mathrm{C}$ overnight. Finally, the membranes were treated with HRP-linked secondary antibodies for $1 \mathrm{~h}$ at RT. The membranes were washed with TBS-T following the binding reaction with each antibody. The detection of each protein was performed using an enhanced chemiluminescence kit (Millipore, Billerica, MA, USA).

Measurement of caspase-3 activity. The treated MIN6N $\beta$-cells were lysed in $500 \mu 1$ lysis buffer consisting of $10 \mathrm{mM}$ Tris- $\mathrm{HCl}$ ( $\mathrm{pH} 7.5), 10 \mathrm{mM} \mathrm{NaH}{ }_{2} \mathrm{PO}_{4} / \mathrm{NaHPO}_{4}(\mathrm{pH} 7.5$ ), $130 \mathrm{mM} \mathrm{NaCl}, 1 \%$ Triton X-100 and $10 \mathrm{mM} \mathrm{NaPPi}$. The activity of caspase- 3 in the lysates was evaluated using a caspase assay kit (BD Biosciences, San Diego, CA, USA) according to the manufacturer's instructions.

Measurement of insulin secretion. The culture medium was collected from the treated cells and the level of insulin released in the medium was measured using a rat/mouse insulin enzyme-linked immunosorbent (ELISA) assay kit (Linco Research Inc., St. Charles, MO, USA) according to the manufacturer's instructions.
Statistical analysis. All the measurements were obtained from at least three independent experiments and the values are expressed as the mean \pm standard error. Statistical analysis was performed using Student's t-test to evaluate significant differences and analysis of variance and Duncan's multiple range tests (SAS, version 9.1; SAS-Institute, Cary, NC, USA) for comparing multiple groups when appropriate. $\mathrm{P}<0.05$ was considered to indicate a statistically significant difference.

\section{Results}

Effect of C3G on cell viability and generation of ROS in the MIN6N $\beta$-cells. High glucose conditions increase the osmolarity in cells, therefore, the MIN6N $\beta$-cells were also cultured with $25 \mathrm{mM}$ mannitol as an osmotic control agent to distinguish between the effects of glucose and osmotic pressure. High glucose significantly decreased the viability of the cells to $72.9 \%$ of the control, whereas no significant decrease in viability was observed following culture with mannitol. The pretreatment of the cells with $\mathrm{C} 3 \mathrm{G}$ at a concentration of $70 \mu \mathrm{g} / \mathrm{ml}$ restored the cell viability to $83.8 \%$ of the control (Fig. 1A). The intracellular ROS levels in the high glucose-treated cells were determined using the ROS-sensitive fluorescent probe, $\mathrm{H}_{2}$ DCF-DA. High glucose markedly increased the levels of intracellular ROS; however, no effects on the intracellular ROS levels were observed following culture with mannitol. Compared with the cells under high glucose conditions, the cells pretreated with $70 \mu \mathrm{g} / \mathrm{ml} \mathrm{C3G}$ exhibited a marked decrease in the high glucose-dependent increase in intracellular ROS levels and green fluorescence intensity (Fig. 1B and C).

Effect of C3G on MIN6N $\beta$-cell apoptosis. To evaluate whether the growth-inhibitory effect of high glucose was associated with 

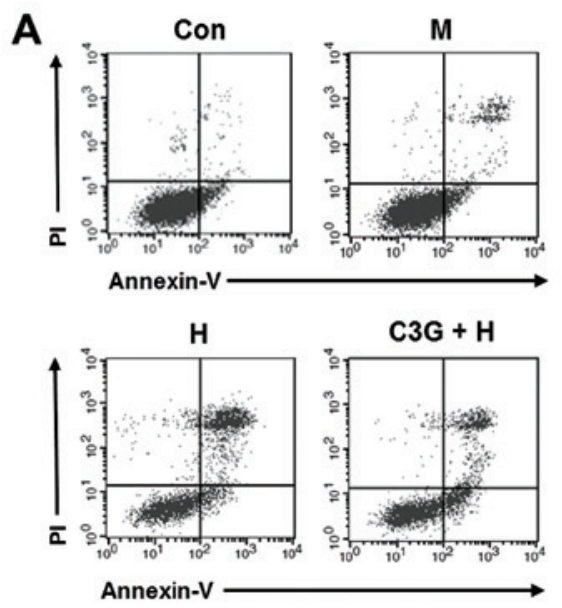

B

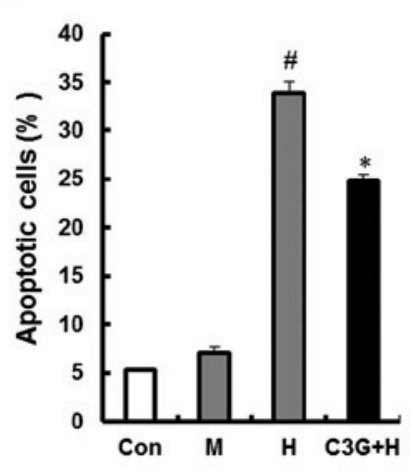

C

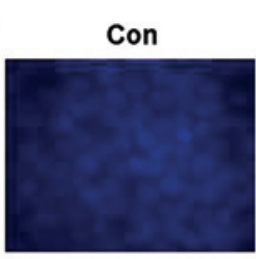

H

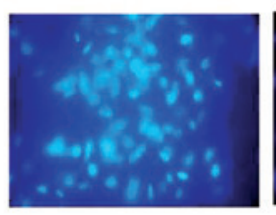

M

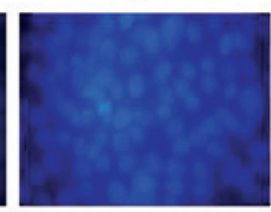

$\mathbf{C} 3 \mathrm{G}+\mathrm{H}$

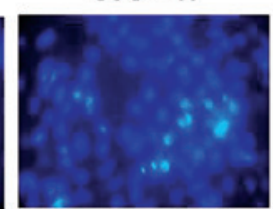

Figure 2. Effect of $\mathrm{C} 3 \mathrm{G}$ on high glucose-induced apoptosis in the MIN6N $\beta$-cells. The cells were cultured with $5.5 \mathrm{mM}$ glucose (Con), $25 \mathrm{mM}$ mannitol (M), $25 \mathrm{mM}$ glucose $(\mathrm{H})$ and $70 \mu \mathrm{g} / \mathrm{ml} \mathrm{C} 3 \mathrm{G}$ with $25 \mathrm{mM}$ glucose $(\mathrm{C} 3 \mathrm{G}+\mathrm{H})$. (A) Apoptotic cells were detected using Annexin V and PI double staining and analyzed by flow cytometry. (B) Sum of the early and late apoptotic cells from the upper right + lower right quadrants. Data represent the mean \pm standard error of three independent experiments. ${ }^{*} \mathrm{P}<0.05$, vs. Con; ${ }^{*} \mathrm{P}<0.05$ vs. $\mathrm{H}$ group. (C) Fluorescent microscopic images of the MIN6N $\beta$-cells stained with Hoechst 33342 (magnification, 400x). CG3, cyanidin-3-glucoside; Con, control; PI, propidium iodide.

A
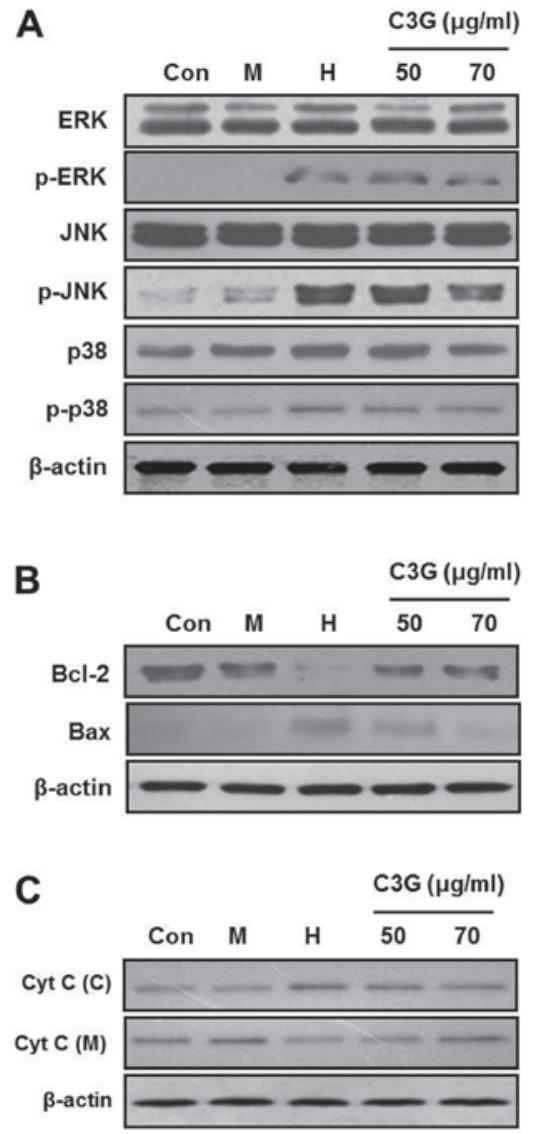

Figure 3. Effect of $\mathrm{C} 3 \mathrm{G}$ on the altered expression of apoptotic-associated proteins in the MIN6N $\beta$-cells treated with high glucose. The cells were cultured with $5.5 \mathrm{mM}$ glucose (Con), $25 \mathrm{mM}$ mannitol $(\mathrm{M}), 25 \mathrm{mM}$ glucose $(\mathrm{H})$ and indicated dose of $\mathrm{C} 3 \mathrm{G}$ with $25 \mathrm{mM}$ glucose $(\mathrm{C} 3 \mathrm{G}+\mathrm{H})$. Subsequently, the cells were harvested and the lysates were prepared. The expression levels of (A) ERK, p-ERK, JNK, p-JNK, p38 MAPK and p-p38 MAPK, (B) Bcl-2 and Bax and (C) fractional cyt c were assessed using western blot analysis. Data represent the mean \pm standard error of three independent experiments. The equal loading of total proteins in each sample was confirmed by the expression of $\beta$-actin. CG3, cyanidin-3-glucoside; Con, control; ERK, extracellular signal-related kinase; p-, phosphorylated; JNK, c-Jun $\mathrm{NH}_{2}$-terminal kinase; MAPK, mitogen-activated protein kinase, Bcl-2, B-cell lymphoma 2; Bax, Bcl-2-associated X protein; cyt c, cytochrome $c$. apoptosis, double-staining was performed using FITC-labeled Annexin V/PI. High glucose caused apoptosis in $33.9 \%$ of the cells, which was significantly higher compared with mannitol. However, pretreatment with $70 \mu \mathrm{g} / \mathrm{ml} \mathrm{C} 3 \mathrm{G}$ significantly inhibited the high glucose-induced apoptotic cell death $(24.85 \%$; Fig. 2A). The fragmentation of DNA upon apoptosis induced by high glucose was confirmed by staining the chromatin of the MIN6N $\beta$-cells using Hoechst 33342. Only the high glucose-treated cells exhibited DNA fragmentation, however, these chromatin changes were decreased following pretreatment with $70 \mu \mathrm{g} / \mathrm{ml} \mathrm{C3G}$ (Fig. 2B).

Effect of C3G on the altered expression of apoptotic-associated proteins in the MIN6N $\beta$-cells. The present study performed western blot analysis to determine the effects of $\mathrm{C} 3 \mathrm{G}$ on the mitogen-activated protein kinase (MAPK) signaling pathway in the MIN6N $\beta$-cells. The cells were cultured under high glucose conditions, with or without $\mathrm{C} 3 \mathrm{G}$, followed by examination of the phosphorylation levels of ERK, JNK and p38. Treatment with C3G (50 and $70 \mu \mathrm{g} / \mathrm{ml})$ led to dose-dependent inhibition of the high glucose-dependent phosphorylation of all the MAPK proteins (Fig. 3A). Apoptosis is initiated via two pathways, the intrinsic pathway is characterized by the release of cytochrome $c$ and the activation of Bcl-2 family proteins, whereas the extrinsic pathway involves activation of apoptosis inducing factor (AIF), caspase-8 and caspase-10 (11). A previous study demonstrated that the phosphorylation of MAPK proteins is involved in the regulation of the mitochondrial permeability-mediated activation of apoptotic proteins, including Bcl-2 family proteins and cytochrome $c$ (12). In the present study, the release of cytochrome $c$ and expression of Bcl-2 family proteins, including Bcl-2 and Bax were confirmed (Fig. 3B). The protein expression of Bcl-2 decreased, whilst that of Bax increased in the high glucose-treated cells. The expression of the $\mathrm{Bcl}-2$ family proteins in the group pretreated with $70 \mu \mathrm{g} / \mathrm{ml} \mathrm{C} 3 \mathrm{G}$ was regulated in a manner similar to the control group. In addition, the present study investigated whether high glucose induced the release of 
A
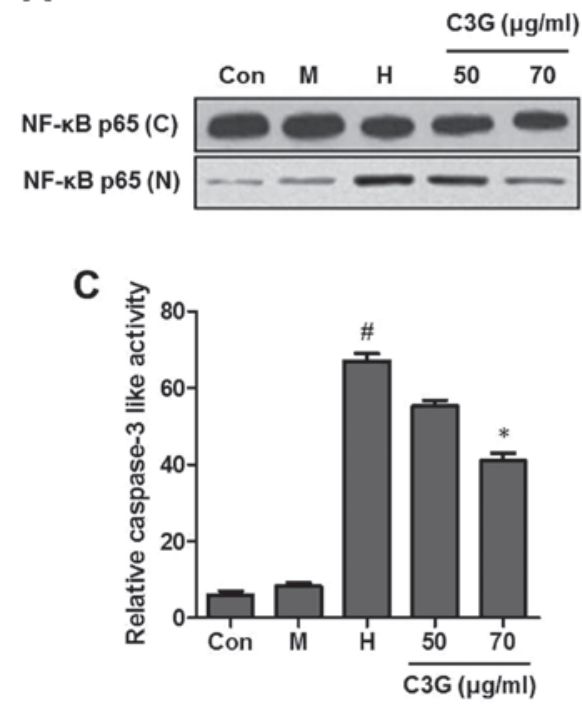

B

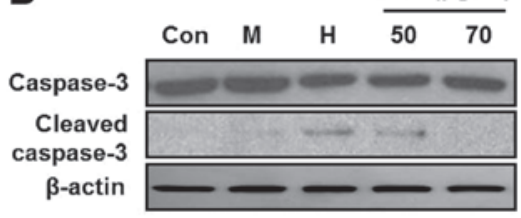

D

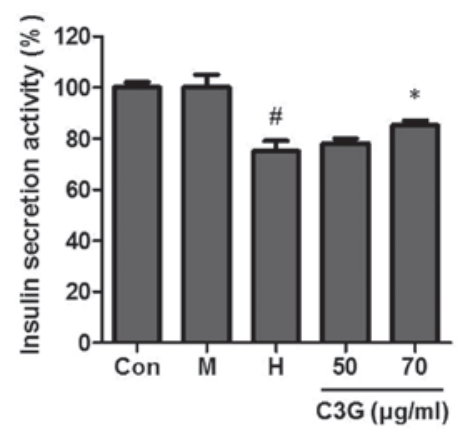

Figure 4. Effect of $\mathrm{C} 3 \mathrm{G}$ on the translocation of NF- $\mathrm{kB}$, activation of caspase-3 and insulin secretion in the MIN6N $\beta$-cells treated with high glucose. The cells were cultured with $5.5 \mathrm{mM}$ glucose (Con), $25 \mathrm{mM}$ mannitol (M), $25 \mathrm{mM}$ glucose $(\mathrm{H})$ and the indicated doses of C3G with $25 \mathrm{mM}$ glucose $(\mathrm{C} 3 \mathrm{G}+\mathrm{H})$. Subsequently, the cells were harvested and the lysates were prepared. The expression levels of fractional (A) NF-кB and (B) caspase-3 and cleaved caspase- 3 were assessed using western blot analysis. The equal loading of the total proteins in each sample was confirmed by the expression of $\beta$-actin. (C) Effect of C3G on caspase-3 activity in the MIN6N $\beta$-cells. (D) Effect of C3G on insulin secretion in the MIN6N $\beta$-cells. Following treatment, the supernatants were collected and insulin release was measured using a rat/mouse insulin ELISA kit. All the experiments were representative of at least the independent experiments.

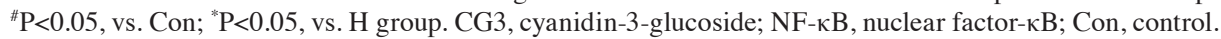

cytochrome $c$ from the mitochondria into the cytosol. Western blot analysis of the cytosolic fraction revealed a significant release of cytochrome $c$ from mitochondria in the cells cultured with high glucose. However, C3G (50 and $70 \mu \mathrm{g} / \mathrm{ml})$ treatment inhibited the release of cytochrome $c$ (Fig. 3C). To investigate whether high glucose induced the extrinsic apoptotic pathway, the expression of AIF and caspase- 8 was examined in the MIN6N $\beta$-cells treated with high glucose. However, no significant promotion of AIF or caspase- 8 activation was observed in high glucose-induced glucotoxicity (data not shown).

Effect of $C 3 G$ on the translocation of $N F-\kappa B$, activation of caspase-3 and insulin secretion in the MIN6N $\beta$-cells. $\mathrm{NF}-\kappa \mathrm{B}$ is involved in oxidative stress-induced cell death in different cell types (12), therefore, the present study examined the translocation of $\mathrm{NF}-\kappa \mathrm{B}$ from the cytosol into the nucleus. High glucose induced the nuclear translocation of NF- $\mathrm{BB}$ p65, however pretreatment with $\mathrm{C} 3 \mathrm{G}$ (50 and $70 \mu \mathrm{g} / \mathrm{ml})$ inhibited the high glucose-induced nuclear translocation of NF- $\kappa \mathrm{B}$ p65 (Fig. 4A). Caspase-3 is important in the execution of apoptosis, therefore, the present study examined the effect of $\mathrm{C} 3 \mathrm{G}$ on the high glucose-induced activation of caspase-3. The cleaved form of caspase-3 was detected in the high glucose-treated group. However, compared with the high glucose-treated group, the group pretreated with C3G (50 and $70 \mu \mathrm{g} / \mathrm{ml})$ exhibited a decrease in the level of cleaved caspase-3 (Fig. 4B). To further investigate the effects of $\mathrm{C} 3 \mathrm{G}$ on caspase- 3 activity, the activity of caspase-3 was analyzed using a caspase-3 assay kit. High glucose treatment significantly increased the activity of caspase-3, however, $\mathrm{C} 3 \mathrm{G}(70 \mu \mathrm{g} / \mathrm{ml})$ significantly decreased the caspase-3 activity (Fig. 4C). The antidiabetic efficacy of $\mathrm{C} 3 \mathrm{G}$ was determined by measuring insulin release in the MIN6N $\beta$-cells using a rat/mouse insulin ELISA kit. Treatment with
$\mathrm{C} 3 \mathrm{G}$ led to an increase in insulin secretion compared with the high glucose-treated control (74.8, vs. 84.2\%; Fig. 4D).

\section{Discussion}

Hyperglycemia causes glucotoxicity in vulnerable cell types and contributes to the generation of intracellular ROS, which results in apoptosis (13). Consequently, ROS have been implicated in the aging process, carcinogenesis, rheumatoid arthritis and inflammation(14). The excessive generation of intracellular ROS by high glucose is particularly deleterious to the pancreas and their levels are correlated with the loss of $\beta$-cell mass, $\beta$-cell dysfunction and pancreas islet destruction (15). In addition, insulin deficiency, caused by the destruction of pancreatic $\beta$-cells, induces long-term hyperglycemia, which leads to different types of diabetic complications and serious pathological effects (16). The blood glucose concentration is increased by various environmental stresses, eating, drinking and smoking habits and thus leads to glucotoxicity in the tissues and organs (17). Therefore, inhibition of the glucotoxicity-induced excessive generation of ROS has been considered to be an important therapeutic target for protecting pancreatic $\beta$-cells in the prevention and/or treatment of diabetes (18).

Previous studies have demonstrated that anthocyanins, which are natural pigments obtained from various plants, have inhibitory effects against ROS and hyperglycemia-induced oxidative stress and, therefore, they are used orally as phytotherapeutic agents $(19,20)$. Antioxidants from natural products have emerged as a novel class of phytotherapeutic agents for diabetes (21). The findings of the present study revealed that $\mathrm{C} 3 \mathrm{G}$ exerted marked antioxidative effects by inhibiting the generation of intracellular ROS and, thus, C3G may be used as a novel therapeutic agent for the prevention and/or treatment of various diseases. 
The high glucose treatment significantly reduced cell viability, however the cell viability was restored following pretreatment with C3G (Fig. 1A). High glucose conditions induce the generation of ROS, which are harmful for pancreatic $\beta$-cells and cause an increase in the rate of apoptosis and DNA fragmentation (22). The $\mathrm{C} 3 \mathrm{G}$ treatment decreased the intracellular ROS generation (Fig. 1B) and the rate of apoptosis in the high glucose-treated MIN6N $\beta$-cells (Fig. 2A and 2B). These results suggested that high glucose increased oxidative stress, defined as cellular damage caused by ROS, and that C3G may attenuate high glucose-induced oxidative stress in the MIN6N pancreatic $\beta$-cells. Additional experiments were performed to evaluate the signaling mechanism underlying the cytoprotection of $\mathrm{C} 3 \mathrm{G}$ against high glucose-induced apoptosis. The phosphorylation of MAPK proteins activated the pro-apoptotic protein Bax. The activated Bax induced the release of cytochrome $c$ from the mitochondria into the cytosol and the cytosolic cytochrome $c$ then activated caspase-3, which was important in the apoptotic pathway and lead to apoptosis. However, the present study also confirmed that pretreatment with $\mathrm{C} 3 \mathrm{G}$ exerted protective effects against high glucose-induced apoptosis by regulating the activation of the intrinsic mitochondrial pathway-mediated proteins. In addition, C3G markedly inhibited the nuclear translocation of NF- $\mathrm{KB}$ in high glucose-treated cells. The phosphorylation of MAPK proteins is important in the translocation of $N F-\kappa B$ into the nucleus (23). The major mechanism underlying the inhibition of $\mathrm{NF}-\kappa \mathrm{B}$ activation by C3G may be through suppressing the phosphorylation and activation of the MAPK and $\mathrm{Bcl}-2$ proteins. Insulin secretion was significantly inhibited in the MIN6N $\beta$-cells exposed to high glucose conditions. In particular, pretreatment with $70 \mu \mathrm{g} /$ $\mathrm{ml} \mathrm{C} 3 \mathrm{G}$ led to increased insulin secretion.

In conclusion, the present study demonstrated that $\mathrm{C} 3 \mathrm{G}$ isolated from mulberry fruits protected the pancreatic $\beta$-cells by inhibiting apoptosis via regulation of the intrinsic apoptotic pathway-mediated proteins. These results suggested that $\mathrm{C} 3 \mathrm{G}$ offers potential as a novel chemopreventative agent for diabetes.

\section{Acknowledgements}

This study was supported by the High Value-added Food Technology Development Program, Ministry of Agriculture, Food and Rural Affairs.

\section{References}

1. Shvarts LS and Shub AI: Side effect of insulin. Klin Med 47: 85-89, 1969.

2. Kim BY, Jung $\mathrm{CH}$, Mok JO and Kim $\mathrm{CH}$ : Factors associated with long-term oral hypoglycemic agent responsiveness in korean patients with type 2 diabetes mellitus. Diabetes Metab J 35: $282-289,2011$

3. Lee NJ, Norris SL and Thakurta S: Efficacy and harms of the hypoglycemic agent pramlintide in diabetes mellitus. Ann Fam Med 8: 542-549,2010.

4. Salimifar M, Fatehi-Hassanabad Z and Fatehi M: A review on natural products for controlling type 2 diabetes with an emphasis on their mechanisms of actions. Curr Diabetes Rev 9: 402-411, 2013.

5. Peng CH, Chyau CC, Chan KC, Chan TH, Wang CJ and Huang CN: Hibiscus sabdariffa polyphenolic extract inhibits hyperglycemia, hyperlipidemia, and glycation-oxidative stress while improving insulin resistance. J Agric Food Chem 59: 9901-9909, 2011.
6. Gupta S, Sharma SB, Prabhu KM and Bansal SK: Protective role of Cassia auriculata leaf extract on hyperglycemia-induced oxidative stress and its safety evaluation. Indian J Biochem Biophys 46: 371-377, 2009.

7. Zhao C, Giusti MM, Malik M, Moyer MP and Magnuson BA Effects of commercial anthocyanin-rich extracts on colonic cancer and nontumorigenic colonic cell growth. J Agric Food Chem 52: 6122-6128, 2004

8. Edirisinghe I, Banaszewski K, Cappozzo J, Sandhya K, Ellis CL, Tadapaneni R, et al: Strawberry anthocyanin and its association with postprandial inflammation and insulin. Br J Nutr 106: 913-922, 2011.

9. Noda Y, Kaneyuki T, Mori A and Packer L: Antioxidant activities of pomegranate fruit extract and its anthocyanidins: delphinidin, cyanidin, and pelargonidin. J Agric Food Chem 50: 166-171, 2002.

10. Oak MH, Bedoui JE, Madeira SV, Chalupsky $\mathrm{K}$ and Schini-Kerth VB: Delphinidin and cyanidin inhibit PDGF (AB)-induced VEGF release in vascular smooth muscle cells by preventing activation of $\mathrm{p} 38$ MAPK and JNK. Br J Pharmacol 149: 283-290, 2006.

11. Pan MH, Chiou YS, Cheng AC, Bai N, Lo CY, Tan D, et al: Involvement of MAPK, Bcl-2 family, cytochrome $\mathrm{c}$, and caspases in induction of apoptosis by 1,6-O,O-diacetylbritannilactone in human leukemia cells. Mol Nutr Food Res 51: 229-238, 2007.

12. Saldeen J and Welsh N: p38 MAPK inhibits JNK2 and mediates cytokine-activated iNOS induction and apoptosis independently of NF- $\mathrm{KB}$ translocation in insulin-producing cells. Eur Cytokine Netw 15: 47-52, 2004

13. Yu T, Jhun BS and Yoon Y: High-glucose stimulation increases reactive oxygen species production through the calcium and mitogenactivated protein kinase-mediated activation of mitochondrial fission. Antioxid Redox Signal 14: 425-437, 2011.

14. Palsamy P and Subramanian S: Ameliorative potential of resveratrol on proinflammatory cytokines, hyperglycemia mediated oxidative stress, and pancreatic beta-cell dysfunction in streptozotocin-nicotinamide-induced diabetic rats. J Cell Physiol 224: 423-432, 2010

15. Noh $\mathrm{H}$ and $\mathrm{Ha} \mathrm{H}$ : Reactive oxygen species and oxidative stress. Contrib Nephrol 170: 102-112, 2011.

16. Kim WH, Lee JW, Suh YH, Lee HJ, Lee SH, Oh YK, et al: AICAR potentiates ROS production induced by chronic high glucose: roles of AMPK in pancreatic beta-cell apoptosis. Cell Signal 19: 791-805, 2007.

17. Zou R, Yang L, Xue J, Ke M, Huang Q, Huang Q, et al: RIP140 mediates hyperglycemia-induced glucotoxicity in beta-cells via the activation of JNK and ERK1/2 signaling pathways. Diabetes Res Clin Pract doi:10.1016/j.diabres.2012.12.008.

18. Lee SH, Park MH, Park SJ, Kim J, Kim YT, Oh MC, Jeong Y, Kim M, Han JS and Jeon YJ: Bioactive compounds extracted from Ecklonia cava by using enzymatic hydrolysis protects high glucose-induced damage in INS-1 pancreatic $\beta$-cells. Appl Biochem Biotechnol 167: 1973-1985, 2012.

19. Harris CS, Asim M, Saleem A, Haddad PS, Arnason JT and Bennett SA: Characterizing the cytoprotective activity of Sarracenia purpurea L., a medicinal plant that inhibits glucotoxicity in PC12 cells. BMC Complement Altern Med 12: 245, 2012.

20. Zhu W, Jia Q, Wang Y, Zhang Y and Xia M: The anthocyanin cyanidin-3-O-beta-glucoside, a flavonoid, increases hepatic glutathione synthesis and protects hepatocytes against reactive oxygen species during hyperglycemia: Involvement of a cAMP-PKA-dependent signaling pathway. Free Radic Biol Med 52: 314-327, 2012.

21. Hays NP, Galassetti PR and Coker RH: Prevention and treatment of type 2 diabetes: current role of lifestyle, natural product, and pharmacological interventions. Pharmacol Ther 118: 181-191, 2008.

22. Lee SH, Park MH, Kang SM, Ko SC, Kang MC, Cho S, Park PJ, Jeon BT, Kim SK, Han JS and Jeon YJ: Dieckol isolated from Ecklonia cava protects against high-glucose induced damage to rat insulinoma cells by reducing oxidative stress and apoptosis. Biosci Biotechnol Biochem 76: 1445-1451, 2012.

23. Becatti M, Prignano F, Fiorillo C, Pescitelli L, Nassi P, Lotti T, et al: The involvement of Smac/DIABLO, p53, NF- $\kappa \mathrm{B}$, and MAPK pathways in apoptosis of keratinocytes from perilesional vitiligo skin: Protective effects of curcumin and capsaicin. Antioxid Redox Signal 13: 1309-1321, 2010. 